\title{
Desempenho ponderal de novilhas mestiças Holandês $\times$ Zebu submetidas a duas estratégias de suplementação mineral ${ }^{1}$
}

\author{
Felipe Nogueira Domingues ${ }^{2 *}$, José Fernando Coelho da Silva ${ }^{3}$, Hernán Maldonado \\ Vásquez ${ }^{3}$, Ricardo Augusto Mendonça Vieira ${ }^{3}$, Fernando Silveira Ferolla ${ }^{2}$, Fábio Nunes Lista $^{2}$ \\ ${ }^{1}$ Trabalho parcialmente financiado pelo CNPq e pela UENF. \\ 2 Programa de Pós-graduação em Produção Animal LZNA/CCTA/UENF. \\ ${ }^{3}$ LZNA/CCTA/UENF, RJ. Bolsista do CNPq.
}

RESUMO - Avaliou-se o desempenho ponderal de novilhas em regime de pastejo rotacionado consumindo dois tipos de suplemento mineral. Utilizaram-se 25 novilhas Holandês $\times$ Zebu, 9 como animais reguladores e 16 como animais-prova, divididas em quatro tratamentos: capim-mombaça e sal seletivo (MSS); capim-mombaça e sal comercial (MSC); capimelefante e sal seletivo (ESS); e capim-elefante e sal comercial (ESC). O ganho médio diário (GMD) foi calculado pesando-se os animais-prova a cada 28 dias após jejum alimentar de 16 horas. Foram avaliados os consumos de matéria seca de lâmina foliar verde (CMSLFV) e a digestibilidade aparente da matéria seca de lâmina foliar verde (DMSLFV) utilizando-se óxido crômico como marcador externo e fibra em detergente neutro indigerível como marcador interno. Foram mensurados os consumos dos suplementos minerais e avaliados os teores de matéria seca, proteína bruta, fibra em detergente neutro e de $\mathrm{Ca}, \mathrm{P}, \mathrm{K}, \mathrm{Mg}, \mathrm{Na}, \mathrm{Cu}, \mathrm{Zn}, \mathrm{Fe}$ e $\mathrm{Mn}$ somente em amostras de lâmina foliar. O delineamento estatístico utilizado foi o inteiramente casualizado em esquema fatorial $2 \times 2$ (gramínea e mistura mineral). Cada tratamento foi composto por quatro animais, de modo que cada animal constituiu uma unidade experimental. Apenas os minerais $\mathrm{Cu}, \mathrm{Na}$ e $\mathrm{Zn}$ foram encontrados em quantidades insuficientes nas forrageiras. Os CMSLFV não foram influenciados por nenhuma das variáveis estudadas nem por suas interações. Houve interação sal mineral $\times$ gramínea para a DMSLFV. O GMD foi influenciado apenas pelas gramíneas; o desempenho dos animais que consumiram o capim-elefante foi superior. A composição nutricional do capimelefante foi ligeiramente superior à do capim-mombaça, o que provavelmente proporcionou melhor desempenho aos animais deste tratamento.

Palavras-chave: consumo voluntário, ganho médio diário, sal seletivo, suplementação mineral

\section{Ponderal performance of crossbred Holstein $\times$ Zebu heifers submitted to two mineral supplementations strategies}

\begin{abstract}
The ponderal performance of heifers under rotational grazing fed two types mineral supplement was evaluated. A total of 25 heifers Holstein $\times$ Zebu, including nine regulator animals and 16 test animals, was divided into four treatments: mombaçagrass (Panicum maximum, CV. Mombaça) with selective salt (MSS), mombaçagrass with commercial salt (MSC), elephantgrass (Pennisetum purpureum, CV. Napier) with selective salt (ESS) and elephantgrass with commercial salt (ESC). Average daily live weight gain (DWG) was calculated by weighing the test animal every 28 days after fasting of 16 hours. Dry matter intake (CMSLFV) and apparent digestibility (DMSLFV) of green leaf blade were evaluated with chromium oxide and indigestible neutral detergent fiber, as external and internal markers, respectively. Mineral supplement intake was measured and the levels of dry matter, crude protein, and of $\mathrm{Ca} . \mathrm{P}, \mathrm{K}, \mathrm{Mg}, \mathrm{Na}, \mathrm{Cu}, \mathrm{Zn}, \mathrm{Fe}$ and $\mathrm{Mn}$ only in grass leaves samples. A completely randomized design in $2 \times 2$ factorial arrangement (grass and minera mix), was used. Each treatment was composed by four animals, and each animal as considered a experimental unit. Only $\mathrm{Cu}$, Na and $\mathrm{Zn}$ were deficient in the forages. The CMSLFV were not affected by the studied variables and no significant interactions were observed. There was interaction between salt mix and grass for DMSLF. The DWG was affected only by grasses, the performance that ingested elephantgrass was higher. The nutritional composition of the elephantgrass was slightly better than that of mombaçagrass what probably provided better weight gains for the animals in this treatment.
\end{abstract}

Key Words: daily weight gain, voluntary intake, mineral supplementation, selective salt

Este artigo foi recebido em 15/12/2005 e aprovado em 27/8/2007.

Correspondências devem ser enviadas para felipend@uenf.br.

Endereço atual: Programa de Pós-graduação em Zootecnia da UNESP-Jaboticabal. Rua José de Jesus Marconato, 91, Jardim Nova Aparecida Jaboticabal/SP, CEP: $14883-330$. 


\section{Introdução}

A bovinocultura é uma atividade relativamente importante para a sustentabilidade econômica dos municípios do norte do estado do Rio de Janeiro, onde $40 \%$ das propriedades rurais têm a pecuária como principal atividade (Ponciano et al., 2002). As condições de criação nesta região se assemelham às do restante do país, uma vez que o pasto constitui a principal fonte de nutrientes.

A recria de novilhas é uma fase importante dos sistemas de produção, visto que estes animais serão as futuras matrizes no plantel. O principal objetivo da alimentação e do manejo de novilhas de reposição é a obtenção de vacas de excelente produção. No entanto, a fase de recria não recebe a mesma atenção pelos produtores, que alegam não obter lucro com estes animais, que ainda não estão em lactação.

Este argumento, na maioria das vezes, é comum nas propriedades cuja principal atividade é a produção de leite. Essa postura tem que ser revista, uma vez que a redução da idade ao primeiro parto contribui para a diminuição do custo de produção da propriedade. Isso porque estes animais entram em lactação com idade menor e permanecem no rebanho por mais tempo; com isso, há maior produção por animal durante sua permanência no plantel.

Nos últimos 30 anos, a suplementação mineral em rebanhos bovinos sofreu considerável incremento, sobretudo em virtude da maciça propaganda por empresas que produzem suplementos minerais. Esse fenômeno foi, por um lado, positivo, pois induziu à conscientização dos produtores quanto às deficiências minerais como causa de enfermidades e de prejuízos econômicos no sistema de produção. Como conseqüência, ocorreu uma intensificação na utilização da suplementação mineral para os rebanhos. Neste contexto, o método mais utilizado para suplementar ou corrigir uma eventual deficiência é o emprego das misturas minerais comercias (MMC). Essas MMC, em geral, contêm cálcio $(\mathrm{Ca})$, fósforo $(\mathrm{P})$, magnésio $(\mathrm{Mg})$, enxofre $(\mathrm{S})$, sódio $(\mathrm{Na})$, zinco $(\mathrm{Zn})$, manganês $(\mathrm{Mn})$, ferro $(\mathrm{Fe})$, cobre $(\mathrm{Cu})$, cobalto (Co), iodo (I) e selênio ( $\mathrm{Se}$ ) em sua composição. Outras MMC ainda contêm em suas fórmulas cromo ( $\mathrm{Cr}$ ) e níquel (Ni); portanto, pressupõe-se que esses minerais sejam dieteticamente importantes aos bovinos (Peixoto et al., 2003).

A forragem produzida em solos tropicais pode ser deficiente em grande número de macro e microelementos inorgânicos necessários ao animal, o que caracteriza a necessidade de se incluir, em uma mistura mineral, os elementos deficientes para que se alcance produção mais eficiente e lucrativa.

A deficiência de Na é considerada deficiência mundial (diagnosticada em todos os continentes), por isso, todos os rebanhos devem ter acesso a fontes ricas deste mineral. No Brasil, além do $\mathrm{Na}$, a deficiência de $\mathrm{P}$ é considerada a principal, seguida pelas deficiências de $\mathrm{Co}$ e $\mathrm{Cu}$ (Moraes et al., 1999; Tokarnia et al., 2000). Eventualmente, em algumas regiões, pode haver solos deficientes em $\mathrm{Ca}, \mathrm{Mg}, \mathrm{K}, \mathrm{Mn}, \mathrm{Fe}$, Se, Zn e I (Moraes, 2001a, b).

A variabilidade na intensidade e no número de minerais deficientes de uma região em comparação a outra é muito grande, principalmente em um país com dimensões continentais como o Brasil.

A maioria dos trabalhos publicados no Brasil não trata o assunto do ponto de vista da produção animal, e sim, do ponto de vista clínico-patológico, o que dificulta a descoberta da representatividade de cada deficiência mineral e seu impacto no sistema de produção. Por isso, torna-se necessário descobrir quais minerais são realmente deficientes em cada região, de modo a customizar a suplementação mineral.

Objetivou-se com este trabalho testar alternativas à suplementação mineral que não impliquem perda de produtividade, redução do consumo e diminuição da digestibilidade do pasto disponível. Para isso, avaliou-se o desempenho ponderal de novilhas leiteiras mestiças, manejadas em sistemas de pastejo rotacionado com duas forrageiras, Panicum maximum (cv. Mombaça) e Pennissetum purpureum Schum. (cv. Napier), suplementados com mistura mineral comercial (MMC), com quase todos nutrientes minerais e uma mistura mineral seletiva (MMS), contendo $\mathrm{Na}, \mathrm{P}, \mathrm{Cu}$ e $\mathrm{Co}$.

\section{Material e Métodos}

O experimento foi conduzido durante 165 dias, com a efetiva coleta de dados iniciada após 44 dias de adaptação à rotina de trabalhos. Contudo, o consumo de suplementos minerais nos tratamentos será avaliado graficamente de acordo com os dias de ocupação dos piquetes até a obtenção de seu ponto de estabilização para posteriores análises. A área experimental, localizada em Campos dos Goytacazes ( $21^{\circ} 44^{\prime} 47^{\prime \prime} \mathrm{S}, 41^{\circ} 18^{\prime} 24^{\prime \prime} \mathrm{W}$ e altitude média de $12 \mathrm{~m}$ ), pertence à mesorregião Norte Fluminense, com 3,36 ha de pastos de Panicum maximum (cv. Mombaça) e Pennissetum purpureum, Schum (cv. Napier), subdivididos para o estabelecimento de quatro sistemas de suplementação. Cada piquete do experimento possuía $600 \mathrm{~m}^{2}$.

No período de adaptação, as forrageiras estavam acima da altura ideal para o início do pastejo, portanto, optou-se por um pastejo com carga animal mais elevada no período de adaptação para que ocorresse maior consumo de capim no estádio avançado de crescimento. Após o pastejo, no 
período de adaptação, retiraram-se os animais excedentes e, em seguida, efetuou-se o corte de uniformização a $1 \mathrm{~m}$ de altura para todos os piquetes de ambas as espécies de gramíneas.

As pastagens foram manejadas em pastejo com lotação rotacionada, com três dias de ocupação para ambos os capins e com períodos de descanso de 36 e 42 dias, respectivamente, para os capins mombaça e elefante. Os capins foram irrigados de modo que cada piquete, em todos os tratamentos, recebesse a mesma lâmina d'água.

Amostras de solo foram retiradas na profundidade de $20 \mathrm{~cm}$ para análise da composição em micro e macroelementos para utilização como referência na adubação. $\mathrm{O}$ adubo fosfatado foi aplicado para elevar o teor de P para $20 \mathrm{mg} / \mathrm{dm}^{3}$ de solo. A fonte de P utilizada foi o superfosfato simples, aplicado após os primeiros três dias de ocupação de cada piquete, no período de adaptação.

A adubação nitrogenada foi realizada com aplicação de nitrogênio $(200 \mathrm{~kg} / \mathrm{ha})$ na forma de uréia, juntamente com $\mathrm{K}_{2} \mathrm{O}(60 \mathrm{~kg} / \mathrm{ha})$ na forma de cloreto de potássio. As adubações foram realizadas após a saída dos animais dos piquetes e foram parceladas de acordo com o número de rodízios efetuados a partir do início do período de adaptação.

A adubação com micro-nutrientes (FTE-BR12) foi aplicada nas áreas de capim-elefante e de capim-mombaça, juntamente com a primeira adubação nitrogenada e potássica em cobertura, obedecendo à dosagem de $10 \mathrm{~kg} / \mathrm{ha}$ para ambos os capins. A mistura de elementos continha a seguinte composição: $\mathrm{Zn}=9 \%, \mathrm{~B}=1,8 \%, \mathrm{Cu}=0,85 \%, \mathrm{Fe}=$ $3,0 \%, \mathrm{Mn}=2,1 \%$ e $\mathrm{Mo}=0,1 \%$, segundo o fabricante.

A disponibilidade de forragem foi avaliada pela técnica dos quadrados (Lopes et al., 2000) no dia anterior à entrada dos animais nos piquetes. Foram coletadas três amostras de capim por piquete, cortadas a $30 \mathrm{~cm}$ do solo com auxílio de um quadrado de $1 \mathrm{~m}$ de lado para a demarcação da área a ser amostrada. O local de coleta foi pré-estabelecido com a utilização de uma trena e uma haste de ferro de $1,80 \mathrm{~m}$. A coleta foi feita a cada $15 \mathrm{~m}$ sobre uma diagonal traçada entre dois vértices do piquete e na coleta subseqüente utilizou-se como referência a outra diagonal (Penati, 2002). As três amostras cortadas foram misturadas e homogeneizadas para obtenção da amostra composta para composição morfológica (caule/ bainha, material morto e lâmina foliar verde).

A pressão de pastejo foi regulada para oferta de $4 \mathrm{~kg}$ de matéria seca (MS) de lâmina foliar verde (MSLFV) para cada $100 \mathrm{~kg}$ de peso vivo (PV). Foi definido que, se algum tratamento ficasse com oferta de forragem abaixo do valor estipulado, todos os tratamentos seriam ajustados por aquele de menor oferta.
Foram utilizadas 25 novilhas Holandês $\times$ Zebu com peso vivo (PV) de $243 \mathrm{~kg} \pm 55 \mathrm{~kg}$, sendo 9 animais reguladores e 16 animais-prova, distribuídos pelos quatro tratamentos, de modo que cada tratamento apresentasse média, desvio-padrão e coeficiente de variação dos pesos próximos. Todos os animais foram identificados (brinco), submetidos ao controle de endo e ectoparasitas e vacinados contra febre aftosa. O desempenho ponderal dos animais foi quantificado por meio de pesagens a cada 28 dias, após jejum de sólidos por aproximadamente 16 horas; as pesagens foram integralizadas ao final do período experimental.

Os tratamentos experimentais foram: capim-elefante + sal seletivo $(E S S)=15$ piquetes; capim-elefante + sal comercial $($ ESC $)=15$ piquetes; capim-mombaça + sal seletivo $($ MSS $)=$ 13 piquetes; capim-mombaça + sal comercial $($ MSC $)=13$ piquetes.

A composição mineral utilizada neste experimento (Tabela 1) foi baseada nas exigências nutricionais dos animais (NRC, 2001) e no histórico de deficiências minerais na região, identificadas nos trabalhos de Tokarnia et al. (1971), Moraes et al. (1999) e Tebaldi et al. (2000).

O sal seletivo foi misturado em misturador tipo "Y" por 15 minutos. O sal seletivo foi composto de $(\mathrm{kg} / 100 \mathrm{~kg}$ de SS) $74,7 \mathrm{~kg}$ de cloreto de sódio, $25,0 \mathrm{~kg}$ de fosfato bicálcico, $0,3 \mathrm{~kg}$ de sulfato de cobre e $0,02 \mathrm{~kg}$ de sulfato de cobalto.

Os cochos para o fornecimento das misturas minerais ficaram próximos à fonte de água para todos os tratamentos: todos possuíam a mesma dimensão e suas medidas lineares sempre superiores a $4 \mathrm{~cm}$ por animal. $O$ consumo de minerais equivaleu à diferença entre a quantidade de suplemento ofertada no momento em que os animais acessavam os piquetes e a quantidade remanescente ao final do período de ocupação. Em seguida, o resultado foi dividido pela lotação no período de três dias e pelo período de ocupação a fim de obter a quantidade de mineral consumida em $\mathrm{g} / \mathrm{kg}$ $\mathrm{PV} / \mathrm{dia}$.

Para a medição do consumo de forragem, foram utilizados o óxido crômico $\left(\mathrm{Cr}_{2} \mathrm{O}_{3}\right)$ como indicador externo e a fibra em detergente neutro indigerível (FDNi) como indicador interno. $\mathrm{O} \mathrm{Cr}_{2} \mathrm{O}_{3}$ foi administrado em dois períodos de 16 dias (10 de adaptação e 6 de coleta) durante o período experimental, sendo o primeiro período em julho e o segundo em outubro de 2004. $\mathrm{O} \mathrm{Cr}_{2} \mathrm{O}_{3}$ foi administrado em duas doses diárias: 3 g pela manhã (a partir das 7:30) e $3 \mathrm{~g}$ à tarde (a partir das 16:00), perfazendo um total de $6 \mathrm{~g} /$ animal/dia. Nos mesmos horários do fornecimento do $\mathrm{Cr}_{2} \mathrm{O}_{3}$, nos seis últimos dias de cada período, efetuou-se a coleta de fezes, diretamente no reto dos animais. 
Tabela 1 - Composição mineral das misturas sal seletivo e sal comercial

\begin{tabular}{|c|c|c|}
\hline Nutriente & Sal seletivo & Sal comercial ${ }^{1}$ \\
\hline $\mathrm{Ca}(\mathrm{g} / \mathrm{kg})$ & 60,00 & 120,00 \\
\hline$P(g / k g)^{2}$ & 45,00 & 88,00 \\
\hline $\mathrm{S}(\mathrm{g} / \mathrm{kg})$ & 0,41 & 12,00 \\
\hline $\mathrm{Na}(\mathrm{g} / \mathrm{kg})$ & 276,30 & 126,00 \\
\hline Co $(\mathrm{mg} / \mathrm{kg})$ & 40,00 & 55,50 \\
\hline $\mathrm{Cu}(\mathrm{mg} / \mathrm{kg})$ & 763,50 & $1.530,00$ \\
\hline $\mathrm{Fe}(\mathrm{mg} / \mathrm{kg})$ & - & $1.800,00$ \\
\hline $\mathrm{I}(\mathrm{mg} / \mathrm{kg})$ & - & 75,00 \\
\hline $\mathrm{Mn}(\mathrm{mg} / \mathrm{kg})$ & - & $1.300,00$ \\
\hline $\mathrm{Se}(\mathrm{mg} / \mathrm{kg})$ & - & 15,00 \\
\hline $\mathrm{Zn}(\mathrm{mg} / \mathrm{kg})$ & & $3.630,00$ \\
\hline F (máximo) $(\mathrm{mg} / \mathrm{kg})$ & $45 \overline{0}, 00$ & 880,00 \\
\hline
\end{tabular}

${ }^{1}$ Composição segundo o fabricante.

2 Solubilidade do fósforo em ácido cítrico 2\%, mínimo de 90\%, no fosfato bicálcico.

Para as análises bromatológicas, foram coletadas amostras das gramíneas retiradas dos piquetes do mesmo modo efetuado para o ajuste da oferta de forragem. Uma amostra foi retirada nos meses de junho, agosto e setembro e duas amostras nos meses de julho e outubro que coincidiram com os períodos de fornecimento do $\mathrm{Cr}_{2} \mathrm{O}_{3}$. Estas amostras, juntamente com as amostras fecais coletadas na ampola retal dos animais, foram armazenadas em congelador a $-15^{\circ} \mathrm{C}$ para posterior análise.

As amostras de capim foram descongeladas à sombra ao final do experimento de campo e separadas em bainha mais colmo, material morto e lâmina foliar verde, para secagem a $60^{\circ} \mathrm{C}$ por 72 horas. De forma semelhante, as amostras de fezes após a secagem, foram pesadas, moídas e reunidas em uma amostra composta por período para cada animal, relativa às coletas da manhã e da tarde com base na MS. As amostras de capim e de fezes foram processadas em moinho tipo Willey, com peneira de crivos de $1 \mathrm{~mm}$ de diâmetro, e acondicionadas em potes de plástico com tampa. Posteriormente, foram feitas as análises de MS e proteína bruta (PB), conforme descrito por Silva \& Queiroz (2002), e fibra em detergente neutro, segundo Van Soest, citado por Silva \& Queiroz (2002), somente nas amostras de lâmina foliar. Para análise dos minerais, as amostras de capim (lâmina foliar verde) sofreram digestão nitro-perclórica, segundo Miyazawa et al. (1999). As leituras para Ca, Mg, Cu, Fe, Mn e $\mathrm{Zn}$ foram feitas utilizando-se aparelho de espectrometria por absorção atômica, para o $\mathrm{Na}$ e o $\mathrm{K}$, aparelho de espectrofotometria por emissão induzida por chama; e o P em aparelho de colorimetria pelo método do molibdato, segundo Malavolta et al. (1989). As amostras fecais sofreram digestão nitro-perclórica e foram submetidas à dosagem do teor de Cr utilizando-se um espectrofotômetro UV visível a $440 \mathrm{~nm}$.
As amostras de forragem utilizadas para a avaliação do consumo e da digestibilidade aparente da MS de lâmina foliar verde (MSLFV) foram as amostras coletadas nos meses de julho e outubro e a digestibilidade aparente calculada pelo método dos indicadores $\left(\mathrm{Cr}_{2} \mathrm{O}_{3}\right)$.

$\mathrm{O}$ teor de FDNi contido nas amostras de lâmina foliar e de fezes, processadas em moinho com peneira formada de malha com $5 \mathrm{~mm}$ de diâmetro, foi estimado incubando-se aproximadamente $0,8 \mathrm{~g}$ dos respectivos materiais em sacos de náilon (porosidade de $50 \mathrm{~mm}$ ), com superfície total de $49 \mathrm{~cm}^{2}$, por 144 horas em rúmen de animal fistulado, mantido exclusivamente a pasto.

O delineamento estatístico utilizado foi o inteiramente casualizado (DIC) em esquema fatorial $2 \times 2$ com duas gramíneas e duas misturas minerais (sal). Cada tratamento foi composto de quatro animais, de modo que cada animal correspondeu a uma unidade experimental. O modelo estatístico utilizado para análise do ganho de peso foi o seguinte:

$$
\mathrm{Y}_{\mathrm{ijk}}=\mu+\mathrm{S}_{\mathrm{i}}+\mathrm{G}_{\mathrm{j}}+\mathrm{SG}_{\mathrm{ij}}+\mathrm{e}_{\mathrm{ijk}}
$$

em que: $Y_{i j k}=$ observação referente ao k-ésimo animal, mantido no sistema de pastejo rotacionado sobre a j-ésima gramínea e recebendo o i-ésimo suplemento; $\mu$ = média geral; $\mathrm{S}_{\mathrm{i}}=$ efeito relativo ao i-ésimo suplemento $(\mathrm{i}=1,2$.$) ;$ $\mathrm{G}_{\mathrm{j}}=$ efeito relativo à j-ésima gramínea $(\mathrm{j}=1,2.) ; \mathrm{SG}_{\mathrm{ij}}=$ efeito da interação suplemento $\times$ gramínea, e $\mathrm{e}_{\mathrm{ijk}}=$ erro aleatório associado às pressuposições de normalidade, independência e homocedasticidade de sua distribuição.

O modelo estatístico utilizado para análise do consumo e digestibilidade das forragens foi:

$\mathrm{Y}_{\mathrm{ijkl}}=\mu+\mathrm{S}_{\mathrm{i}}+\mathrm{G}_{\mathrm{j}}+\mathrm{SG}_{\mathrm{ij}}+\mathrm{A}_{\mathrm{k}(\mathrm{ij})}+\mathrm{P}_{1}+\mathrm{SP}_{\mathrm{il}}+\mathrm{GP}_{\mathrm{j} 1}+\mathrm{SPG}_{\mathrm{ijl}}$ em que: $Y_{\mathrm{ijkl}}=$ observação referente ao k-ésimo animal, mantido no sistema de pastejo rotacionado com a j-ésima gramínea recebendo o i-ésimo suplemento no l-ésimo período; $\mu=$ média geral; $\mathrm{S}_{\mathrm{i}}=$ efeito relativo ao i-ésimo suplemento $(\mathrm{i}=1,2.) ; \mathrm{G}_{\mathrm{j}}=$ efeito relativo à $\mathrm{j}$-ésima gramínea $(j=1,2.) ; G_{i j}=$ efeito da interação suplemento $\times$ gramínea; $\mathrm{A}_{\mathrm{k}(\mathrm{ij})}=$ efeito do k-ésimo animal dentro do i-ésimo suplemento e j-ésima gramínea; $\mathrm{P}_{1}=$ efeito relativo ao l-ésimo período $(1=1,2.) ; \mathrm{SP}_{\mathrm{il}}=$ efeito da interação suplemento $\times$ período; $\mathrm{GP}_{\mathrm{j} 1}=$ efeito da interação gramínea $\times$ período; $\mathrm{SPG}_{\mathrm{ijl}}=$ efeito da interação de sal $\times$ gramínea $\times$ período; $\mathrm{e}_{\mathrm{ijkl}}=$ erro aleatório associado às pressuposições de normalidade, independência e homocedasticidade de distribuição.

\section{Resultados e Discussão}

Os teores mais elevados de $\mathrm{PB}$ e relativamente baixos de FDN das duas gramíneas nos dois sistemas de suplementação mineral, comparativamente aos resultados 
da literatura, podem ter sido ocasionados pela adubação e irrigação no período do experimento e ao fato das gramíneas não terem atingido porte alto, o que não ocasionou o efeito de diluição dos nutrientes, como também não resultou na deposição de fibra para a sustentação da planta. Outro ponto relevante que provavelmente ocasionou estes maiores teores de PB e menores teores de FDN é que, neste trabalho, foram analisadas apenas as amostras de lâmina foliar verde para simulação da ingestão de nutrientes pelos animais. A opção de analisar apenas as amostras de lâmina foliar verde para representar a forragem consumida explica-se pela preferência dos bovinos por material foliar. A presença de colmos bem desenvolvidos (material grosseiro) - que não eram consumidos pelos animais e não considerados na simulação e que remanesciam no resíduo após pastejo - também pode justificar o menor teor de fibra nas amostras.

Os teores de $\mathrm{Ca}, \mathrm{P}, \mathrm{Mg}, \mathrm{Mn}, \mathrm{K}$ e Fe foram superiores às exigências dos animais, principalmente o $\mathrm{Fe}$ e o Mn, contudo, as concentrações dos minerais avaliados estiveram acima da exigência e abaixo do limite de toxidez para os animais. Os níveis de $\mathrm{Cu}$, $\mathrm{Zn}$ e Na nas forrageiras não foram suficientes para suprir as exigências das novilhas, ou seja, $10 \mathrm{mg} / \mathrm{kg}, 32 \mathrm{mg} / \mathrm{kg}, 0,8 \mathrm{~g} / \mathrm{kg}$ na base MS, respectivamente, conforme NRC (2001). Os teores médios de Na determinados neste estudo foram baixos, o que está de acordo com Tokarnia et al. (2000) ao concluírem que o Na é o mineral de deficiência universal nas forrageiras.

Os consumos médios diários de MS de lâmina foliar verde (CMSLFV, \%PV/dia) não foram influenciados por nenhum dos fatores estudados nem por suas respectivas interações $(\mathrm{P}>0,05)$. As médias gerais desta variável foram de 3,73, 3,29, 2,98 e 3,13\% PV/dia para os tratamentos MSS, MSC, ESS e ESC, respectivamente, com coeficiente de variação de $21,87 \%$ e desvio-padrão de $\pm 0,77 \% \mathrm{PV} /$ dia (considerando os períodos de julho e outubro). Optou-se pela demonstração do resultado do CMSLFV mediante uma média geral abrangendo os dois períodos de avaliação pelo fato de o período não ter influenciado o CMSLFV $(\mathrm{P}>0,05)$. Os valores de CMSLFV encontrados neste experimento foram numericamente maiores que os resultados descritos na literatura, particularmente os valores preditos constantes no NRC (2001).

As médias gerais da DMSLFV encontradas neste experimento foram de 60,$08 ; 56,33 ; 58,21$ e $63,44 \%$ para os tratamentos MSS, MSC, ESS e ESC, respectivamente, com coeficiente de variação para a digestibilidade de $8,44 \%$ e desvio-padrão de $\pm 5,54 \%$ (considerando os períodos de julho e outubro). A demonstração dos resultados da DMSLV também foi apresentada por uma média geral abrangendo os dois períodos (julho e outubro), pois não houve efeito significativo para período. Houve interação significativa das variáveis sal mineral e gramínea para a DMSLFV, o que implicou na necessidade de desdobramento para constatação do efeito principal. A DMSLFV do capimmombaça não diferiu quando os animais foram alimentados com o sal seletivo ou o sal comercial. Esta variável em relação ao capim-elefante foi maior quando os animais foram alimentados com sal comercial quando comparado ao sal seletivo. A DMSLFV do capim-elefante foi igual a do capim-mombaça quando os animais foram alimentados com o sal seletivo. Quando os animais foram alimentados com o sal comercial, a DMSLFV do capim-elefante foi maior que a do capim-mombaça.

O ganho médio diário (GMD) observado para os animais nos tratamentos MSS, MSC, ESS e ESC foram de 0,677, $0,547,0,777$ e $0,796 \mathrm{~kg} \mathrm{PV} /$ dia, com coeficiente de variação de $14,44 \%$ e desvio-padrão de $\pm 0,136 \mathrm{~kg}$ PV/dia. O desempenho ponderal dos animais neste experimento atendeu às expectativas, uma vez que novilhas mestiças Holandês $x$ Zebu têm o primeiro parto aos 24 meses e precisam alcançar o peso recomendado de $330 \mathrm{~kg}$ aos 15 meses de idade, o que equivale a um ganho médio diário de $0,667 \mathrm{kgPV} / \mathrm{dia}$, fato observado neste experimento para todos os tratamentos, exceto no grupo MSC.

Com relação ao GMD, não foi observado efeito significativo para as fontes sal mineral e interação sal mineral $\times$ gramínea. No entanto, ocorreu efeito significativo para gramínea $(\mathrm{P}<0,05)$, o que permitiu concluir que o desempenho foi melhor nos animais manejados no sistema rotacionado sobre o capim-elefante.

Tabela 2 - Composição das forrageiras (\%MS)

\begin{tabular}{|c|c|c|c|c|c|c|c|c|c|c|c|c|}
\hline Tratamento & MS (\%) & FDN & PB & $\mathrm{Ca}$ & $\mathrm{P}$ & K & $\mathrm{Mg}$ & $\mathrm{Na}$ & $\mathrm{Cu}$ & $\mathrm{Zn}$ & $\mathrm{Fe}$ & $\mathrm{Mn}$ \\
\hline MSS & 24,25 & 65,21 & 14,85 & 0,47 & 0,22 & 1,32 & 1,18 & 20,00 & 6,15 & 32,86 & 153,6 & 213,0 \\
\hline ESS & 18,71 & 62,69 & 16,15 & 0,42 & 0,29 & 1,78 & 0,95 & 14,29 & 8,34 & 31,66 & 129,5 & 146,9 \\
\hline ESC & 19,20 & 64,51 & 16,46 & 0,44 & 0,28 & 1,88 & 0,97 & 17,14 & 7,95 & 27,37 & 130,6 & 104,4 \\
\hline
\end{tabular}

MSS = capim-mombaça + sal seletivo, MSC = capim-mombaça + sal comercial, ESS = capim-elefante + sal seletivo, ESC = capim-elefante + sal comercial . 
O capim-elefante apresentou teores médios de $\mathrm{PB}(16,15$ e 16,46\%), FDN (62,69 e64,51\%)eDMSLFV (58,21 e 63,44\%), respectivamente, para os tratamentos ESS e ESC, enquanto o capim-mombaça apresentou teores médios de PB de 14,85 e $14,04 \%$, FDN de 65,21 e 64,56\% e DMSLFV de 60,08 e $56,33 \%$, respectivamente, para os tratamentos MSS e MSC. Esta superioridade na qualidade nutricional da MS de lâmina foliar pode ter favorecido o desempenho das novilhas que o consumiam.

Em razão da grande variação nos resultados de consumo dos suplementos, analisados graficamente pelas medidas de dispersão, constatou-se que o consumo estabilizou-se aos 195 dias da implantação do experimento, coincidindo com os últimos 60 dias do tempo experimental.

O consumo médio de suplemento mineral foi de 0,19 , 0,07, 0,16 e 0,21 g/kg PV/dia para os tratamentos MSS, MSC, ESS e ESC, respectivamente. Como não houve efeito significativo do suplemento nem da interação suplemento $\times$ gramínea no desempenho dos animais, procedeu-se à análise conjunta do consumo de suplemento para obtenção das médias de consumo do sal seletivo e sal comercial de 0,18 e $0,14 \mathrm{~g} / \mathrm{kg} \mathrm{PV} /$ dia, respectivamente. O consumo médio total de suplemento pelos animais no experimento foi de $0,16 \mathrm{~g} / \mathrm{kgPV} /$ dia, o coeficiente de variação foi de $44,72 \%$ e o desvio-padrão de $\pm 0,07$.

Considerando os valores obtidos (Tabela 3), é possível concluir que os animais tiveram suas exigências nutricionais em Ca, P, K, Mg, Fe e Mn atendidas exclusivamente pelas forrageiras.
A deficiência de Na nas forrageiras foi evidente, visto que ambas as gramíneas supriram no máximo 2,5\% das exigências nutricionais dos animais. Apenas os tratamentos MSS, ESS e ESC tiveram as exigências dos animais atendidas com o somatório do $\mathrm{Na}$ contido tanto no suplemento como na forrageira. O tratamento MSC supriu apenas 35,72\% das exigências dos animais, mesmo combinado ao $\mathrm{Na}$ contido no capim-mombaça consumido.

Os teores de $\mathrm{Cu}$ das forrageiras não foram suficientes para atender às necessidades dos animais. As novilhas atingiram níveis de consumo de $\mathrm{Cu}$ suficientes para atender às exigências nutricionais nos tratamentos MSS, ESS e ESC. Aquelas que receberam o tratamento MSC tiveram apenas $90,68 \%$ da exigência em Cu satisfeita. Este resultado corrobora o diagnóstico sugerido por Tokarnia et al. (1971) e Tebaldi et al. (2000) de que existe deficiência deste elemento nas áreas pastoris da região norte fluminense.

As amostras de pasto relativas aos tratamentos MSS e ESS apresentaram teores de $\mathrm{Zn}$ numericamente superiores aos das amostras coletadas nos tratamentos MSC e ESC. Portanto, a quantidade de $\mathrm{Zn}$ na forragem ingerida pelas novilhas nos tratamentos com o sal seletivo supriu suas exigências nutricionais. Para os tratamentos MSC e ESC, o teor de $\mathrm{Zn}$ contido nas forragens e no suplemento consumidos possibilitou o atendimento à exigência deste nutriente para o desempenho esperado. Apesar de os tratamentos com sal seletivo terem suprido as exigências, a inclusão desse mineral justificou-se pelo fato de os níveis terem se

Tabela 3 - Consumo médio de minerais por tratamento e fonte

\begin{tabular}{|c|c|c|c|c|c|c|c|c|c|}
\hline Tratamento & \multicolumn{9}{|c|}{ Elemento consumido no volumoso $(\mathrm{g} / \mathrm{dia})^{1}$} \\
\hline MSS & 17,64 & 8,34 & 49,39 & 43,87 & 74,60 & 22,95 & 122,58 & 572,88 & 795,83 \\
\hline ESS & 12,58 & 8,59 & 53,22 & 28,49 & 42,64 & 24,90 & 94,49 & 386,51 & 438,36 \\
\hline \multirow[t]{2}{*}{ ESC } & 13,73 & 8,81 & 58,77 & 30,49 & 53,70 & 24,92 & 85,74 & 409,17 & 326,88 \\
\hline & \multicolumn{9}{|c|}{ Elemento consumido no sal mineral $(\mathrm{g} / \mathrm{dia})^{1}$} \\
\hline MSC & 0,84 & 0,62 & 0,00 & 0,00 & 882,00 & 10,71 & 25,41 & 12,60 & 9,10 \\
\hline ESS & 0,96 & 0,72 & 0,00 & 0,00 & 4420,80 & 12,22 & 0,00 & 0,00 & 0,00 \\
\hline \multirow[t]{2}{*}{ ESC } & 2,52 & 1,85 & 0,00 & 0,00 & 2646,00 & 32,13 & 76,23 & 37,80 & 27,30 \\
\hline & \multicolumn{9}{|c|}{ Exigência de acordo com NRC (2001) (g/dia) ${ }^{2}$} \\
\hline MSS & 15,29 & 8,21 & 17,90 & 4,10 & 2984,02 & 37,30 & 119,36 & 160,39 & 82,06 \\
\hline
\end{tabular}

MSS = capim-mombaça + sal seletivo, MSC = capim-mombaça + sal comercial, ESS = capim-elefante + sal seletivo, ESC = capim-elefante + sal comercia

1 Consumo dos elementos oriundos do volumoso e do suplemento mineral considerando um animal de $100 \mathrm{~kg}$ de PV.

2 Adaptado do NRC (2001), exigência de bezerras para idade ao primeiro parto aos 24 meses e à idade adulta, com $680 \mathrm{~kg}$. 
mantido próximos ao exigido, o que implica a necessidade de $\mathrm{Zn}$ suplementar para animais em pastejo na região.

\section{Conclusões}

A recria de novilhas nas regiões pastoris do norte do estado do Rio de Janeiro em pastagens com capins mombaça e elefante adubados e irrigados, em sistema rotacionado, exige a suplementação mineral com fontes ricas em $\mathrm{Na}, \mathrm{Cu}$ e Zn. Nestas mesmas circunstâncias, não há necessidade de suplementar o pasto com fontes contendo $\mathrm{Ca}, \mathrm{P}, \mathrm{Mg}$, $\mathrm{Mn}, \mathrm{K}$ e Fe e o capim-elefante cv. Napier proporciona melhor desempenho de novilhas em comparação ao capimmombaça. Essas assertivas baseiam-se em resultados experimentais de curta duração, portanto, são necessários estudos de longa duração sobre a viabilidade econômica dos sistemas para generalização das informações.

\section{Literatura Citada}

LOPES, R.S.; FONSECA, D.M.; CÓSER, A.C. et al. Avaliação de métodos para estimação da disponibilidade de forragem em pastagem de capim-elefante. Revista Brasileira de Zootecnia, v.29, n.1, p.40-47, 2000.

MALAVOLTA, E.; VITTI, G.C.; OLIVEIRA, S.A.D.E. Avaliação do estado nutricional das plantas: princípio e aplicação. Piracicaba: POTAFOS, 1989. 201p.

MIYAZAWA, M.; PAVAN, M.A.; MURAOKA, K. et al. Análises químicas de tecido vegetal. In: SILVA, F.C. (Ed.) Manual de análises químicas de solos, plantas e fertilizantes. Brasília: 1999. p.172-223.

MORAES, S.S. Importância da suplementação mineral para bovinos de corte. Campo Grande: EMBRAPA - CNPGC, 2001a. 26p. (Documentos, 114).
MORAES, S.S. Principais deficiências minerais em bovinos de corte. Campo Grande: EMBRAPA - CNPGC, 2001b. 27p. (Documentos, 112).

MORAES, S.S.; TOKARNIA, C.H.; DÖBEREINER J. Deficiências e desequilíbrios de microelementos em bovinos e ovinos em algumas regiões do Brasil. Pesquisa Veterinária Brasileira, v.19, n.1, p.19-33, 1999.

NATIONAL RESEARCH COUNCIL - NRC. Nutrient requirements of dairy cattle. 7.ed. Washington, D.C.: National Academic Press, 2001. 280p.

PEIXOTO, P.V.; MALAFAIA, P.; MIRANDA, L.V. et al. Eficiência reprodutiva de matrizes bovinas de corte submetidas a três diferentes tipos de suplementação mineral. Pesquisa Veterinária Brasileira, v.23, n.3, p.125-130, 2003.

PENATI, A.M. Estudo do desempenho animal e produção do capim tanzânia (Panicum maximum, Jacq.) em um sistema rotacionado de pastejo sob irrigação em três níveis de resíduo pós-pastejo. Piracicaba: Escola Superior de Agricultura Luiz de Queiroz, 2002. 117p. Tese (Doutorado em Agronomia) - Escola Superior de Agricultura Luiz de Queiroz, 2002.

PONCIANO, N.J.; SOUZA, P.M.; MATA, H.T.C. Análise da viabilidade econômica da fruticultura nas Regiões Norte e Noroeste Fluminense. In: CONGRESSO BRASILEIRO DE ECONOMIA E SOCIOLOGIA RURAL, 40., 2002, Passo Fundo. Anais... Passo Fundo: 2002. (CD-ROM).

SILVA, D.J.; QUEIROZ, A.C. Análise de alimentos (métodos químicos e biológicos). 3.ed. Viçosa, MG: Editora UFV, 2002. $235 \mathrm{p}$.

TEBALDI, F.L.H.; COELHO DA SILVA, J.F.; VASQUEZ, H.M. et al. Composição mineral das pastagens das regiões norte e noroeste do estado do Rio de Janeiro. 2. Manganês, ferro, zinco, cobre, cobalto, molibdênio e chumbo. Revista Brasileira de Zootecnia, v.29, n.2, p.616-629, 2000.

TOKARNIA, C.H.; GUIMARÃES, J.A.; CANELLA, C.F.C. et al. Deficiências de cobre e cobalto em bovinos e ovinos em algumas regiões do Brasil. Pesquisa Agropecuária Brasileira, v.6, p.61-77, 1971 .

TOKARNIA, C.H.; DÖBEREINER, J.; PEIXOTO, P.V. et al. Deficiências minerais em animais de fazenda, principalmente bovinos. Pesquisa Veterinária Brasileira, v.20, n.3, p.127138,2000 . 